\title{
Anaesthetic Related Peri-Operative Complications During Caesarean Delivery at the University Teaching Hospital, Lusaka, Zambia
}

\author{
Chakana $C^{1}$, Kinnear $J^{2}$, and Bould $D^{3}$ \\ 'Depertment of Anesthesia, University Teaching Hospital, P/Bag RW 1X.Lusaka, Zambia, 260977662777,chakscoli@yahoo.co.uk \\ ${ }^{2}$ Postgraduate medical institute, Anglia Ruskin University, Cambridge and Chelmsford \\ ${ }^{3}$ Children's Hospital of Eastern Ontario, Ottawa, Ontario, Canada \\ Corresponding Author: \\ ${ }^{1}$ Depertment of Anaesthesia, University Teaching Hospital, \\ P/Bag RW 1X. Lusaka, Zambia, 260977662777,chakscoli@yahoo.co.uk
}

\begin{abstract}
Background: Caesarean deliveries are increasingly performed at the University Teaching Hospital (UTH), Lusaka, with a 2012 audit report indicating a rate of $17.8 \%$. The procedure is a major surgical intervention and results in higher morbidity than vaginal delivery. Part of this morbidity and mortality during caesarean delivery results from the anaesthesia relating to the surgery. However, information on the extent of anaesthetic related complications associated with caesarean deliveries in low resource settings such as at UTH is lacking. This study endeavoured to explore this aspect.
\end{abstract}

Objectives: To determine the frequency of anaesthetic related perioperative complications during caesarean delivery at the UTH, Lusaka, Zambia.

Study Design: A prospective observational study documenting the anaesthetic related complications in women undergoing caesarean delivery at UTH. About 246 consecutive parturients undergoing caesarean deliveries were enrolled in the study.

Methodology: All women who presented for caesarean delivery at UTH in Lusaka, Zambia from January 12, 2014, to July 12, 2014, and met the inclusion criteria were recruited into the study. Information on the patient and her management was obtained from the patient's medical records. Participants were followed up from the time they were taken into theatre, during the procedure until the time they left the recovery room postoperatively, and any complication observed was documented.
Hypotension, possible aspiration, failed intubation, conversion from spinal to general anaesthesia, severe hypoxemia, and deaths were the main outcome measures. A descriptive analysis was performed. All significant variables were included in the final multivariable logistic model. All tests were set at $95 \%$ confidence interval (CI) and a P-value of $<0.05$ was considered statistically significant. Results: No mortality was recorded out of the 246 parturients enrolled for the study. The average age was 28 years. Thirty-four cases $(13.8 \%)$ received general anaesthetic while 212 cases $(86.2 \%)$ had spinal anaesthetic. Obstructed labour 79 cases $(32.1 \%)$ and previous caesarean sections 68 cases $(27.6 \%)$ were among the cesarean deliveries indications. Perioperative complications recorded included, 172 cases $(69.9 \%)$ of hypotension, 6 cases $(11.1 \%)$ had failed intubation, 5 cases $(9.3 \%)$ possibly aspirated, 20 cases $(9.4 \%)$ had failed spinal technique needing conversion to general anaesthetic, 6 cases $(3.1 \%)$ had a high spinal block. Severe hypoxemia intraoperatively and postoperatively was noted in 16 cases $(6.5 \%)$ and 7 cases $(2.8 \%)$ respectively. There were no statistically significant associations among the complications with the age of parturients, ASA status, the grade of the anaesthetist, category of caesarean sections, indication for caesarean sections or gestational age.

Conclusion: There are many anaesthetic related complications during caesarean sections occurring at UTH. Future studies are needed to solely look into factors contributing to each of the complications at UTH. 


\section{INTRODUCTION}

Caesarean deliveries are increasingly performed in the University Teaching Hospital (UTH), Lusaka, with a study in 1982 reporting a rate of $7.5 \% .1$ Data from a 2012 audit report indicated a rate of $17.8 \%$. The procedure is a major surgical intervention that has an increased incidence of morbidity compared to vaginal delivery.2 Part of the morbidity and mortality suffered from caesarean delivery is that resulting from the anaesthesia related to the surgery.3,4,5,6 no data describes the anaesthesia associated morbidity and mortality at the University Teaching Hospital (UTH).

Anaesthesia has emerged as an additional risk factor in maternal deaths, and mortality associated with caesarean delivery has been described in several studies.3,4,5,6 These include Lome, Togo reports, with 12 anaesthetic deaths out of 318 caesarean deliveries performed, a rate of $3.8 \%, 7$ Nigeria, with 84 maternal deaths out of 2323 caesarean deliveries, with anaesthesia accounting for 6 (rate of 7.1\%).6 A study was done in Kampala, Uganda, showed anaesthesia to be the direct cause of 24 maternal deaths in the seven years reviewed, four and another study from Nigeria reported $9 \%$ of maternal mortality as attributable to anaesthesia.5 Despite these alarming figures, anaesthesia as a cause of maternal morbidity and mortality remains underreported mainly in underdeveloped countries.6 Nonetheless, the number of case fatalities associated with anaesthesia remains small compared with those associated with avoidable obstetric factors. 6,7,8

While most studies report mortality rates, many fail to address the rate of avoidable anaesthetic complications. These were defined as any complications arising from general or local anaesthetic, analgesic or other sedation during labour or delivery.9, 10

It is likely that the anaesthetic related mortality and morbidity at UTH were similar to that of other developing countries, but it was not possible to confirm or refute the assumption at the time of the study. These figures are important since they help to identify the reasons behind the avoidable complications. Identifying complications and anaesthetic factors associated with these complications would help in the formulation of a strategy specific to UTH and potentially to Zambia to prevent such avoidable mortality. Improvements to quality care of patients' perioperatively can only be enhanced once anaesthetic related morbidity and mortality are studied. The study endeavoured to explore this aspect. No similar study had been done in Zambia before.

\section{MATERIALS AND METHODS}

This study was conducted in Caesar theatre at the University Teaching Hospital, Lusaka, Zambia. Approval with reference number 010-11-13 was obtained from the University of Zambia Biomedical Research Ethics Committee (UNZABREC). Two hundred and forty-six parturients undergoing either general or spinal anaesthetic technique for emergency, urgent, expedited or elective caesarean delivery were conveniently selected to participate in the study. Exclusion criteria were parturients who declined to participate in the study. Enrollment occurred Mondays to Fridays and also on those weekends when the study investigator was on call. Two theatre nurses assisted the investigator with patient consenting and data collection. The study was for six months from January 12 to July 12 .

A standardized data abstraction form was used to obtain information from patient files. Data collected was from the immediate pre-operative period, intraoperative period, and up to the time, the patient left the recovery room postoperatively. Parturients consented for the study preoperatively.

Anaesthetic related complications with set definitions' recorded included hypotension, aspiration, failed intubation, high spinal block, failed spinal block needing conversion to general anaesthesia, severe hypoxemia and anaesthetic mortality.

All cases were reviewed by the principal investigator, who then gave an opinion regarding the avoidability of the anaesthetic related complication. Data entry errors were checked using double-entry checks by two people entering the data. Range and consistency checks were done. The data was stored on the data capture sheet and analyzed using the Statistical Package for Social Sciences (SPSS version 21, IBM, Armonk).

Descriptive analysis was performed, and appropriate charts produced. Stepwise logistic regression was done to assess individual independent variables in relation to anaesthetic related complications during caesarean deliveries. All significant variables were included in the final 
multivariable logistic model. All tests were set at 95\% confidence intervals $(\mathrm{CI})$ and a $\mathrm{P}$-value of $<0.05$ was considered statistically significant.

\section{RESULTS}

\section{Demographic characteristics of the patients}

A summary of the biographical characteristics of the patients showed the following. Forty-four $(17.9 \%)$ were aged $15-21$ years, $85(34.6 \%)$ were aged 22-28 years, 79 (32.1\%) were aged 29-35 years, and $38(15.4 \%)$ were aged above 35 years. The youngest was aged 15 years; the oldest was aged 47 years; the average age was 28.28 with a standard deviation of 6.323 . Thirty-three (13.4\%) had a gestation period of less than 36 weeks while $213(86.6 \%)$ had a gestation period of more than 36 weeks. One hundred and sixty-four $(66.7 \%)$ had a class 1 ASA status, $66(26.8 \%)$ had a class 2 ASA status, and $16(6.5 \%)$ had a class 3 ASA status. One hundred and eighty-nine $(76.8 \%)$ had a class 1 obstructed labour, $26(10.6 \%)$ had pre-eclampsia, $40(16.3 \%)$ had fetal distress, $17(6.9 \%)$ had ante partum hemorrhage; and $16(6.5 \%)$ had other unspecified indications. The categories of Caesarean sections were: $79(32.1 \%$ were emergencies; 107 (43.5\%) were urgent; $36(14.6 \%)$ were expedited or scheduled; and 24 (9.8\%) were elective and shown in Table 1.

The spinal anaesthetic was used on $212(86.2 \%)$ patients, while $34(13.8 \%)$ received a general anaesthetic. All the 246 patients were alive at the time of leaving the recovery room postoperatively. There were 105 spinals requiring a single attempt at insertion; 74 spinals required a second attempt at insertion, 33 spinals required a third attempt at insertion. There were six failed intubation and 20 failed spinal techniques as shown in table 2 .

Regarding hypotension, 172 (69.9\%) patients experienced a drop of more than $20 \%$ of baseline BP, and $74(30.1 \%)$ patients experienced a drop

Table 1: Indications for and category of caesarean deliveries

\begin{tabular}{|c|c|c|c|}
\hline Variable & Values & Frequency $(n=246)$ & Percent (\%) \\
\hline \multirow{6}{*}{$\begin{array}{l}\text { Indication for } \\
\text { Caesar }\end{array}$} & Previous caesarean section & 68 & 27.6 \\
\hline & Obstructed labour & 79 & 32.1 \\
\hline & Pre-eclampsia & 26 & 10.6 \\
\hline & Fetal distress & 40 & 16.3 \\
\hline & Antepartum hemorrhage & 17 & 6.9 \\
\hline & Others & 16 & 6.5 \\
\hline \multirow{4}{*}{$\begin{array}{c}\text { Category of } \\
\text { Caesar }^{38}\end{array}$} & Emergency & 79 & 32.1 \\
\hline & Urgent & 107 & 43.5 \\
\hline & Expedited/scheduled & 36 & 14.6 \\
\hline & Elective & 24 & 9.8 \\
\hline
\end{tabular}

Mallampati; 44 (17.9\%) had a class 2 Mallampati, 8 had a class 3 Mallampati, and 5 had a class 4 Mallampati.

Further results revealed that three $(1.2 \%)$ patients had anaemia of pregnancy with $\mathrm{Hb}$ less than $10 \mathrm{~g} / \mathrm{dl}, 21(8.5 \%)$ patients had known hypertension before falling pregnant, $6(2.4 \%)$ had known asthma, $2(.2 \%)$ had known diabetes, and 1 $(.4 \%)$ had known tuberculosis.

\section{Indications for and category of caesarean deliveries}

The study revealed that $68(27.6 \%)$ patients had previous caesarean section, 79 (32.1\%) had of less than $20 \%$ of baseline BP. Twenty (9.4\%) patients had a conversion from spinal to general anaesthesia. Six (3.1\%) patients had a high spinal block. Five $(9.3 \%)$ patients had possible aspiration, $16(6.5 \%)$ patients had severe hypoxemia intraoperatively (oxygen saturation less than $85 \%$ ) while $7(2.8 \%)$ patients had severe hypoxemia postoperatively. It was further observed that 178 (72.4\%) complication cases could have been avoided (Table 2). 
Table 2: Anaesthetic complications during caesarean deliveries

\begin{tabular}{|c|c|c|c|}
\hline Variable & Value & Frequency $(n *)$ & Percentage (\%) \\
\hline \multirow{2}{*}{ Failed intubation $n=54$} & Yes & 6 & 11.1 \\
\hline & No & 48 & 88.9 \\
\hline \multirow{2}{*}{ Hypotension $n=246$} & Drop of more than $20 \%$ of baseline BP & 172 & 69.9 \\
\hline & Drop of less than $20 \%$ of baseline BP & 74 & 30.1 \\
\hline \multirow{2}{*}{$\begin{array}{l}\text { Conversion from Spinal to } \\
\text { general anaesthesia } n=212\end{array}$} & Yes & 20 & 9.4 \\
\hline & No & 192 & 90.6 \\
\hline \multirow{2}{*}{ High spinal block $n=192$} & Yes & 6 & 3.1 \\
\hline & No & 186 & 96.9 \\
\hline \multirow{2}{*}{ Possible aspiration $n=54$} & Yes & 5 & 9.3 \\
\hline & No & 49 & 90.7 \\
\hline \multirow{2}{*}{$\begin{array}{l}\text { Severe Intraoperatively } \\
\text { hypoxemia } n=246\end{array}$} & Yes; Oxygen saturation less than $85 \%$ & 16 & 6.5 \\
\hline & No; Oxygen saturation greater than $85 \%$ & 230 & 93.5 \\
\hline \multirow{2}{*}{$\begin{array}{l}\text { Severe Postoperatively } \\
\text { hypoxemia } n=246\end{array}$} & Yes; Oxygen saturation less than $85 \%$ & 7 & 2.8 \\
\hline & No; Oxygen saturation greater than $85 \%$ & 239 & 97.2 \\
\hline
\end{tabular}

A categorized summary of the complications that could have been avoided revealed the following. Thirty-five (19.7\%) of these cases were anaesthetist related; $19(10.7 \%)$ were equipment related; 93 $(52.2 \%)$ were drugs-related; and 31 (17.4\%) were organizational related as shown in table 3.

Table 3: complications that could have been avoided

\begin{tabular}{|c|c|c|}
\hline Factor & Frequency $n=178$ & Percent (\%) \\
\hline $\begin{array}{l}\text { Anaesthetic related } \\
\text { - inadequate pre-operative pt preparation } \\
\text { - lack of experience } \\
\text { - poorly supervised anaesthetic trainee } \\
\text { - lack of preloading pt with intravenous fluids } \\
\text { - poor pt positioning during insertion of spinal } \\
\text { - wrong dosing }\end{array}$ & 35 & 19.7 \\
\hline $\begin{array}{l}\text { Equipment related } \\
\text { - lack of spinal needles } \\
\text { - lack of different sizes of laryngoscope blades } \\
\text { - poor lighting laryngoscopes } \\
\text { - poorly functional pulse oximeter probes }\end{array}$ & 19 & 10.7 \\
\hline $\begin{array}{l}\text { Drug-related } \\
\text { - lack of antacid prophylaxis drugs } \\
\text { - lack of desired vasoconstrictors }\end{array}$ & 93 & 52.2 \\
\hline $\begin{array}{l}\text { Organizational related } \\
\text { - inconsistencies in drug supplies and their quality } \\
\text { - lack of consumables } \\
\text { - lack of monitoring equipment } \\
\text { - lack of trained personnel } \\
\text { - shortage of staff } \\
\text { - unavailability of blood products }\end{array}$ & 31 & 17.4 \\
\hline Total & 178 & 100 \\
\hline
\end{tabular}

